\title{
TGFbeta Inhibitor LY3200882
}

National Cancer Institute

\section{Source}

National Cancer Institute. T GFbeta Inhibitor LY3200882. NCI Thesaurus. Code C132013.

An orally bioavailable agent that targets transforming growth factor-beta (TGFb), with potential antineoplastic activity. Upon administration, LY3200882 specifically targets and binds to T GFb, which prevents both the binding of T GFb to its receptor T GFbR and T GFbmediated signal transduction. This may lead to a reduction in T GFb-dependent proliferation of cancer cells. The T GFb signaling pathway is often deregulated in tumors, and plays a key role in the regulation of cell growth, differentiation, apoptosis, motility, invasion, angiogenesis, and various immune responses. 